\title{
LISTAS DE VÉRTIGO
}

Umberto ECO, El vértigo de las listas (Vertigine della lista, 2009). Trad. María Pons Irazazábal. Barcelona, Lumen, 2009, 408 pp.

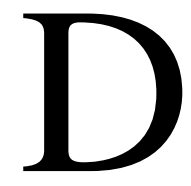
ecidme ahora, Musas que habitáis las moradas del Olimpo (pues vosotras sois diosas y en todo estáis presentes y todo lo sabéis, en tanto que nosotros solamente rumor oímos y nada sabemos), quiénes los generales y los jefes de los dánaos eran» (Ilíada, canto II). Con esta cita de la Ilíada homérica podría comenzar El vértigo de las listas, que nos ofrece un apasionante viaje por la literatura y el arte a través de una antología de las listas en la historia de la literatura occidental, desde Homero hasta nuestros días. Una obra en la línea de la Historia de la belleza (2004) y la Historia de la fealdad (2007), que complementa y aúna texto e imagen, literatura y arte, dirigida a un lector general, no necesariamente especializado, que quedará cautivado por la belleza del libro y el cuidado trabajo de Eco.

El vértigo de las listas surge ante el encargo al alessandrino, por parte del Louvre, de la organización de una serie de conferencias y exposiciones alrededor de un tema vertebrador. Eco quiso que este fueran las listas en sus más diversas manifestaciones, nóminas que ya abundaban en su obra e interesaban al autor desde sus primeros estudios juveniles centrados en los textos medievales y en James Joyce que, por supuesto, también tienen cabida en este largo viaje.

Como ya he comentado, Eco parte de Homero y los dos tipos de lista que ofrece, la descripción finita del escudo de Aquiles (Ilíada, canto XVIII) y el célebre catálogo infinito de combatientes del ejército griego (Ilíada, canto II) para sentar las bases de su desarrollo posterior y establecer un canon propio de la lista. Así, desde un primer momento, nos presenta la poética del "todo está aquí", representada por el escudo y, de otro lado, la poética del "etcétera", ilustrada por la nómina de combatientes. Esta última, que relaciona con el topos de la indecibilidad, es la que más le interesa y la que ocupará la mayor parte de su discurso. 
Lo indecible. Frente a algo inmensamente grande o desconocido el autor de la obra literaria o artística nos propone un ejemplo, un simple muestreo, como hiciera Virgilio en la Eneida o Dante en el Paraíso de la Divina Comedia al no poder nombrar a todos los ángeles del cielo por ignorar su número. El topos de la indecibilidad alcanza a nombres, cosas y lugares. La historia de la literatura está llena de listas de objetos: de sustancias (Shakespeare, Macbeth), flores (Marino, Adonis), instrumentos musicales (Mann, Doctor Faustus), pero también de mirabilia y listas de portentos como objeto de curiosidad científica, de Wunderkammer, de colecciones y tesoros, repertorios que Eco irá desglosando capítulo a capítulo.

Sin embargo, la lista no se queda anclada en las páginas de los libros sino que también queda reflejada en las más diversas manifestaciones artísticas, porque esta trasciende el texto literario. Muchas obras pictóricas inducen a pensar que lo que ocupa el marco no es un todo, que la obra se extiende más allá de los límites del lienzo. Así ocurre ante la visión de numerosas representaciones pictóricas de batallas con ejércitos alineados al modo homérico, pero también ante las galerías de Pannini, el soberbio Jardín de las delicias del Bosco o el tan comentado fondo de la Mona Lisa.

Muchas veces, la lista sólo responde al más puro amor por la enumeración misma. Y aquí Eco se detiene en la figura de Borges, autor al que admira manifiestamente. En $\mathrm{El}$ aleph Borges contempla por un agujero el mundo «como una lista fatalmente incompleta de lugares, personas, perplejas epifanías» (p. 82). Porque hay listas y listas, y hay que diferenciar entre la práctica (referencial, finita y por presión contextual) y la poética (emotiva, motivada y con tendencia al infinito). Todo ello a pesar de que la lista práctica puede convertirse en poética, ya que todo depende de la intención con la que la contemplemos.

Por supuesto, la lista cuenta con una retórica propia que Eco no olvida analizar, la de la enumeración por acumulación. Esta es frecuente en listas panegíricas o encomiásticas, aparece en gradaciones, y puede constituirse por anáfora, asíndeton o polisíndeton. De otro lado, no obvia la tendencia de la misma al exceso, su gusto por lo deforme, que tan bien ejemplificó Rabelais en su Gargantúa y Pantagruel. Al exceso pero también al desorden, como se observa en la enumeración caótica tantas veces ilustrada a través de los versos de Neruda. Todo un gusto por la acumulación exagerada que va del horror vacui al decadentismo moderno de Huysmans y Wilde.

Por último, y arribando a nuestros días en este placentero viaje, las listas han llegado y colonizado los medios de comunicación de masas en una sociedad caracterizada por ese tan presente "espíritu de bazar" del que hablaba Spitzer. No debemos considerar solamente las listas artísticas, también la lista de la compra o la alineación de un equipo de fútbol, dos ejemplos que nos son a todos cercanos, se nutren 
Reseñas

de su retórica. Tanto es así que la segunda llega a encandilar a oyentes y espectadores, del mismo modo que ocurriera ante la narración por parte de un juglar medieval de una batalla y sus combatientes, o la aclamación de los nombres de los gladiadores ante su salto a la arena del Coliseo, a los que el público también jaleaba fervorosamente. Tan lejos y tan cerca.

En conclusión, El vértigo de las listas es un «libro que forzosamente ha de terminar con un etcétera» (p. 7). Eco logra ofrecer al lector una lista sólida que él sabe incompleta, tomada sobre el modelo de la Biblioteca de Babel borgeana (quizá se eche en falta saber qué sucede con la lista en la literatura oriental). Un libro que, a lo largo de los veintiún capítulos que lo componen, hará las delicias del lector y el crítico al que el autor tan bien ha sabido encandilar, como ha demostrado en tantas otras ocasiones a través de sus estudios o novelas (El nombre de la rosa, El cementerio de Praga), porque como continuaba el célebre canto de la Ilíada, cualquier mortal «la multitud contar no podría ni tampoco nombrarla aunque tuviera diez lenguas y diez bocas y voz inquebrantable, y en el pecho tuviera de bronce los pulmones», $\mathrm{y}$ en este libro de vértigo sólo Eco es capaz de lo indecible.

María CODURAS

Universidad de Zaragoza 